\title{
Aluminum-Free Semiconductors and Packaging
}

M. A. Emanuel

February 3, 2000

U.S. Department of Energy

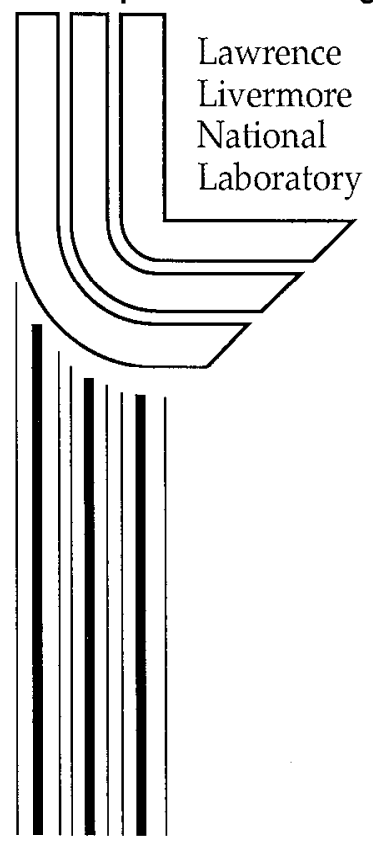




\section{DISCLAIMER}

This document was prepared as an account of work sponsored by an agency of the United States Government. Neither the United States Government nor the University of California nor any of their employees, makes any warranty, express or implied, or assumes any legal liability or responsibility for the accuracy, completeness, or usefulness of any information, apparatus, product, or process disclosed, or represents that its use would not infringe privately owned rights. Reference herein to any specific commercial product, process, or service by trade name, trademark, manufacturer, or otherwise, does not necessarily constitute or imply its endorsement, recommendation, or favoring by the United States Government or the University of California. The views and opinions of authors expressed herein do not necessarily state or reflect those of the United States Government or the University of California, and shall not be used for advertising or product endorsement purposes.

Work performed under the auspices of the U. S. Department of Energy by the University of California Lawrence Livermore National Laboratory under Contract W-7405-Eng-48.

This report has been reproduced directly from the best available copy.

Available to DOE and DOE contractors from the Office of Scientific and Technical Information

P.O. Box 62, Oak Ridge, TN 37831

Prices available from (423) 576-8401

http://apollo.osti.gov/bridge/

Available to the public from the National Technical Information Service

U.S. Department of Commerce 5285 Port Royal Rd., Springfield, VA 22161 http://www.ntis.gov/

OR

Lawrence Livermore National Laboratory Technical Information Department's Digital Library http://www.llnl.gov/tid/Library.html 


\section{Aluminum-Free Semiconductors and Packaging}

Final Report for LDRD Project 97-ERD-111

Principal Investigator: Mark Emanuel

February 3,2000

\section{Introduction}

The use of laser diodes instead of flashlamps to pump solid state lasers generally results in lighter weight, more compact systems with improved cfficicncy and rcliability. These traits are important to a wide variety of applications in military, industrial and other areas. Common solid state laser systems such as yttrium aluminum garnet doped with neodymium or ytterbium (Nd:YAG and $\mathrm{Yb}: Y A G$, respectively) require pump light in the 800 to $1000 \mathrm{~nm}$ range, and such laser diodes have typically been fabricated in the AlGaAs material system on a GaAs substrate. Unfortunately, the presence of aluminum in or near the light-generating regions of these devices appears to limit their high-power performance, so for improved performance attention has turned to the aluminum-free ("Al-free") material system of $\mathrm{InGa} \Lambda \mathrm{sP}$ on a $\mathrm{Ga} \Lambda \mathrm{s}$ substrate. Laser diodes in this system offer the wavelength coverage similar to the $\mathrm{AlGaAs} / \mathrm{GaAs}$ material system, and early results suggest that they may offer improved high-power performance. However, such Alfree diodes are more challenging to manufacture than AlGaAs-based devices. The goal of this LDRD project has been to evaluate Al-free diode technology in comparison with conventional AlGaAs-based structures for use in diode-pumped solid state lasers. This has been done by testing commercially available devices, surveying the literature, developing in-house capability in order to explore new device designs, and by engaging a leading university research group in the field.

\section{Experimental work}

The existing metalorganic chemical vapor deposition (MOCVD) crystal growth reactor was modified to enable the growth of laser diode structures in the InGaAsP material system. This effort comprised the addition of phosphine as a phosphorous precursor. Also, the duplication of trimethylgallium and trimethylindium (sources of gallium and indium, respectively) was necessary in order to avoid precursor switching transients at interfaces between layers containing indium and/or phosphorous. Such transients are not an issue in the AlGaAs material system. After determining reactor conditions necessary for the growth of InGaAsP alloys lattice-matched to the GaAs substrate and then calibrating $\mathrm{p}$ and $\mathrm{n}$ doping in these alloys, laser diode device growth was hegun. 
The first laser structure grown was a single quantum well, separate confinement heterostructure having a $70 \AA$ compressively-strained InGaAs quantum well, InGaAsP waveguide layers (band gap $\sim 1.6 \mathrm{eV}$ ) and InGaP cladding. Except for the quantum well, all layers were lattice-matched to the GaAs substrate. Broad-area lasers, $100 \mu \mathrm{m}$ wide with a $500 \mu \mathrm{m}$ cavity, emitted $200 \mathrm{~mW}$ per uncoated facet at $890 \mathrm{~nm}$ with 1 Amp drive current. This result served to verify the integrity of the new growth equipment and no further work was done to optimize the performance of this structure.

Attention was turned to structures having wider band gap cladding materials in order to achieve better electron confinement and thus improved tolerance of higher temperatures. In order to do realize this, an aluminum-bearing alloy must be used. Although this makes the structure no longer Al-free, this aluminum should not negatively impact the performance of the device since the aluminum is well-separated from the light-generating quantum well region by an Al-free waveguide layer. There are two candidates for the cladding. One can simply add aluminum to the InGaP to create wide band gap InAlGaP cladding layers. This approach has been demonstrated successfully. However, the growth of high quality InAlGaP is challenging, and the use of such a large amount of phosphorous during the growth causes maintenance problems for the reactor, particularly for the system vacuum pump. An alternative to InAlGaP is to use AlGaAs, which is relatively easy to grow. This avoids the use of excessive phosporous and additionally relaxes the requirement of maintaining lattice-match in the cladding since AlGaAs has essentially the same lattice constant as GaAs. The challenge of using AlGaAs cladding layers is achieving a good interface between the $\mathrm{AlGaAs}$ and InGaAsP waveguide layers.

The base structure selected for optimization comprises a quantum well active region surrounded by InGaP waveguide layers and then AlGaAs cladding layers. The band alignments between InGaP and $\mathrm{AlGaAs}$ are such that for $\mathrm{AlAs}$ mole fractions between $\sim 12 \%$ and $\sim 65 \%$ the InGaP/AlGaAs interface is "Type II", meaning that electrons and holes are not confined to the same side of the interface at equilibrium. This might be expected to have negative effects on diode performance owing to poor carrier confinement characteristics and undesired accumulation of carriers near the interface resulting in high optical losses, and in fact this was observed. Several laser structures were grown having cladding AlAs mole fractions varying from $30 \%$ to $70 \%$. Device performance (threshold current and differential quantum efficiency) monotonically improved as more $\mathrm{Al}$ was added until performance leveled of for $65 \%$ and above. A cladding AlAs mole fraction of $70 \%$ was thus selected for further development work.

Next, the problem of wafer defects was addressed. Even though the devices performed well, there was an extremely high density of "hillocks" on the wafer, which was unacceptable because of their yield-reducing potential. The source of the defects was traced to the interface where the AlGaAs p-cladding was grown on the InGaP waveguide layer. Further investigation revealed that the defects were probably small islands of InAs and/or InP grown on the interface during the several second growth interruptions during which phosphine was turned off and arsine was turned on. During this interruption, indium was apparently evaporating off the upstream chamber components, entering the carrier gas stream, and reacting with the arsine or phosphine present to form InAs or InP. Such islands had an extreme lattice mismatch with the GaAs substrate, and subsequent growth of AlGaAs resulted in the formation of misfit dislocations and an enlargement of the underlying islands. When the growth interruption was eliminated, the defects 
disappeared. Unfortunately, laser diodes fabricated from those defect-free wafers exhibited very poor performance. This new development was traced once again to undesired indium in the carrier gas stream. At the start of the AlGaAs layers, there was a large amount of indium in the gas stream but over a few seconds that dropped to a negligible concentration as the indium on the upstream surfaces was buried by AlGaAs deposition. Thus, the first several monolayers grown were actually InAlGaAs, forming a severely strained quantum well at the interface where carriers could recombine non-radiatively, thus reducing device performance. There appeared to be no way to stop this indium evaporation except by growing at a temperature which would be unacceptably low for AlGaAs. Since it could not be stopped, it was decided to attempt to introduce a flow of phosphine during the first few seconds of the growth of the indiumcontaminated AlGaAs in order to form roughly lattice-matched InAlGaAsP. Such a layer would have a higher band gap than the InGaP waveguide layer upon which it was grown and thus would not form a quantum well. After several attempts, a suitable phosphine flow was empirically determined and the performance of the laser devices returned to their previous high levels.

With growth issues identified and solved, work was begun to investigate the performance of devices having different types of active (light generating) regions. Three different active regions were investigated: 1) compressive strained, in which the natural lattice constant of the active region is large than that of the GaAs substrate; 2) tensile-strained, in which the natural lattice constant of the active region is smaller than that of the GaAs substrate, and; 3) strain compensated, in which a compressive strained active region is surrounded by tensile strained layers to give a net strain of zero. The compressive and tensile strained structures exhibitcd similar performance characteristics, while the strain compensated structures exhibited slightly poorer characteristics, perhaps because of the added complexity of their growth. However, reliability testing of the strained compensated devices yielded impressive results. Pulsed testing of such bars showed useful lifetimes of greater than $2 \times 10^{8}$ shots for $750 \mu \mathrm{sec}$ pulse widths. This is to be compared to lifetimes of less than $5 \times 10^{7}$ shots under similar conditions for AlGaAsbased devices. Under $\mathrm{cw}$ testing, projected lifetimes of several thousand hours at $40 \mathrm{~W}$ optical output were observed with the Al-free structures, compared to 1000 hrs for AlGaAs based bars. Preliminary testing of similar wafers by an industrial partner also showed good reliability. Even with very limited test data, it appears that $\mathrm{Al}$-free structures in fact offer some advantages over AlGaAs-based counterparts.

\section{Evaluation of commercial diodes}

While the existing crystal growth reactor was being modified in 1997 to enable Al-free material growth, testing was done on purchased Al-free diode bars. Using a $1 \mathrm{~cm}$ diode bar, emitting at $808 \mathrm{~nm}$, mounted on a microchannel cooler, a projected lifetime of 15,000 hours was obtained at an output power of 30 Watts. This impressive result should be compared to similar lifetimes achieved with AlGaAs-based laser diodes at powers of only 20 Watts, and it strongly suggested that continued investigation of Al-free laser diodes would be fruitful. As technology for both $\mathrm{Al}-$ free and $\mathrm{AlGaAs}$ laser diodes developed, this difference in performance between the two types of laser diodes largely vanished, and in 1999 commercial suppliers of either type of diode offered bars rated at $\sim 50 \mathrm{~W} \mathrm{cw}$ and $>100 \mathrm{~W}$ peak power. 


\section{University interaction}

A leading proponent of Al-free laser diode technology, Prof. Dan Botez of the University of Wisconsin at Madison, was engaged to advise the LLNL Al-free diode effort. His report can be found in Appendix A.

\section{Conclusions}

After considering data from commercial suppliers, an industrial collaborator, and other researchers, as well as our own experimental results, some tentative conclusions have been drawn. When devices with uncoated facets are compared, Al-free active region diodes generally exhibit greater maximum output power before damage (catastrophic optical damage thresholds) and long-term reliability than their AlGaAs-active region counterparts. This is consistent with the simple model of aluminum at the facets reacting with oxygen and water in air and thus degrading the electrical and optical properties of the facets. Much of the early enthusiasm for Alfree devices was based upon this observation. However, useful laser diodes have facet coatings (high reflectivity on the back and low reflectivity, typically 5 to $15 \%$, on the output facet). Thus test comparisons involving uncoated facets, while they might illuminate interesting physical processes, are not conclusive. It has been found by several researchers that judicious treatment and facet coating of $\mathrm{AlGaAs}$ lasers can bring their performance and reliability to levels comparable to those exhibited by Al-free devices. The technical details of these treatments are almost always held proprietary, but they appear to be simple and inexpensive as evidenced by the fact that the price of treated AlGaAs devices is comparable to that of Al-free active region devices. In summary, it would appear that early suggestions of an inherent superiority of Al-free diodes over their AlGaInAs-based counterparts have not been borne out, and in fact the performance of both types of diodes appears to be comparable. 


\title{
High-Power, Al-Free Coherent and Incoherent Diode Lasers
}

\author{
D. Botez \\ Reed Center for Photonics \\ University of Wisconsin - Madison \\ 1415 Engineering Dr., Madison, WI 53706
}

\begin{abstract}
Al-free active-region (ALFA) diode lasers have come of age. Record-high CW and quasi-CW powers have been obtained at $\lambda \sim 0.97 \mu \mathrm{m}$. For wavelengths at and below $0.81 \mu \mathrm{m}$, ALFA-type lasers are definitely superior to Al-containing - active lasers. Al-free lasers both open a whole new wavelength range: 0.7 $0.78 \mu \mathrm{m}$; for commercial use as well as make possible the easy fabrication of watt-range, coherent diode lasers with stable-beam behavior.
\end{abstract}

Keywords: semiconductor diode laser, Al-free active-region (ALFA) lasers, coherent diode lasers

\section{INTRODUCTION}

Al-free diode lasers have been the subject of intense research efforts over the last decade because of several advantages they offer compared to their Al-containing counterparts. First of all, the key advantage of Al-free devices is with respect to lasers that need $\mathrm{Al}$ in their active region: that is, AlGaAs-based lasers for $\lambda<$ $0.83 \mu \mathrm{m}$. From experimental data it has been predicted [1] and later confirmed $[2,3]$ that for the wavelength range $0.78-0.80 \mu \mathrm{m}$, the reliable power level is at least twice higher for ALFA lasers than for AIGaAsactive lasers. This fact is based mainly on comparing the power density at catastrophic optical mirror damage, $\overline{\mathrm{P}}_{\mathrm{COMD}}$, of InGaAsP and AlGaAs-active devices [4]. In the $0.70-0.78 \mu \mathrm{m}$ wavelength range (In)AIGaAs-active devices are unreliable $[5,6]$ due to bulk degradation; which makes ALFA-type devices the only possible reliable sources at the present time.

Another major advantage of Al-free devices is that they employ InGaP, which has low reactivity to oxygen, thus allowing easy regrowths for spatial-mode control (i.e., index-guided devices) $[7,8]$ or frequency-mode control (i.e., distributed-feedback (DFB) lasers) [9]. Other advantages over AlGaAs-based devices are the ability to use strain compensation for better long-term reliability [10] as well as significantly lower series resistances, which allow in turn for higher wallplug efficiencies at high output power levels [11].

\section{THE EQUIVALENT TRANSVERSE SPOT SIZE AND BROAD-WAVEGUIDE CONCEPTS}

The internal power density at COMD is given by [12]:

$$
\overline{\mathrm{P}}_{\mathrm{COMD}}=\left(\frac{1+\mathrm{R}}{1-\mathrm{R}}\right) \frac{\Gamma \times \mathrm{P}_{\max }}{\mathrm{d} \times \mathrm{W}}
$$

where $\mathrm{R}$ is the front-facet reflectivity, $\Gamma$ is transverse optical-mode confinement factor, $\mathrm{P}_{\max }$ is the maximum CW power (at COMD), $d$ is the quantum well(s) thickness, and $W$ is the stripe width. Rearranging eqn(1), one obtains:

$$
\mathrm{P}_{\max , \mathrm{cw}}=\left(\frac{\mathrm{d}}{\Gamma}\right) \mathrm{W}\left(\frac{1-\mathrm{R}}{1+\mathrm{R}}\right) \overline{\mathrm{P}}_{\mathrm{COMD}}
$$


It has been established that for conventionally facet-passivated diodes $\overline{\mathrm{P}}_{\mathrm{COMD}}$ is a function of the activeregion material [4], being in effect inversely proportional [13] with the surface-recombination velocity, $\mathrm{s}$, as long as [14] s $\geq 10^{5} \mathrm{~cm} / \mathrm{s}$. That is, for a given active-region material with $\mathrm{s} \geq 10^{5} \mathrm{~cm} / \mathrm{sec}$ and given stripe width, $P_{\max , c w}$ scales directly with $d / \Gamma$, which is defined as the equivalent (transverse) spot size. [15] One main way to increase $d / \Gamma$ is the use of broad-waveguide separate-confinement-heterostructure (BW-SCH) lasers [15].

Fig. 1 depicts a schematic representation of the BW-SCH structure. A large waveguide width, $t_{c}$, insures a large $d / \Gamma$ value $[15,16]$ as well as low internal cavity loss [15-17], $\alpha_{i}\left(\leq 1 \mathrm{~cm}^{-1}\right)$. In turn, one can use relatively long devices $(1.5-2 \mathrm{~mm})$, which provide for low electrical and thermal resistances. As a result, record-high $\mathrm{CW}$ powers have been achieved from $\mathrm{BW}$-type devices at wavelengths from the visible to the mid-infrared: $1.3 \mathrm{~W}$ at $0.67 \mu \mathrm{m}$ from a $64 \mu \mathrm{m}$-wide aperture [18]; $7 \mathrm{~W}$ at $0.73 \mu \mathrm{m} \mathrm{[19].} \mathrm{8.8W} \mathrm{at} 0.81 \mu \mathrm{m}[12]$, $11 \mathrm{~W}$ at $0.97 \mu \mathrm{m} \mathrm{[11]} \mathrm{from} 100 \mu \mathrm{m}$-wide apertures; and $5.2 \mathrm{~W}$ at $1.47 \mu \mathrm{m}[20], 1.9 \mathrm{~W}$ at $2 \mu \mathrm{m} \mathrm{[21]} \mathrm{from}$ $200 \mu \mathrm{m}$-wide apertures.

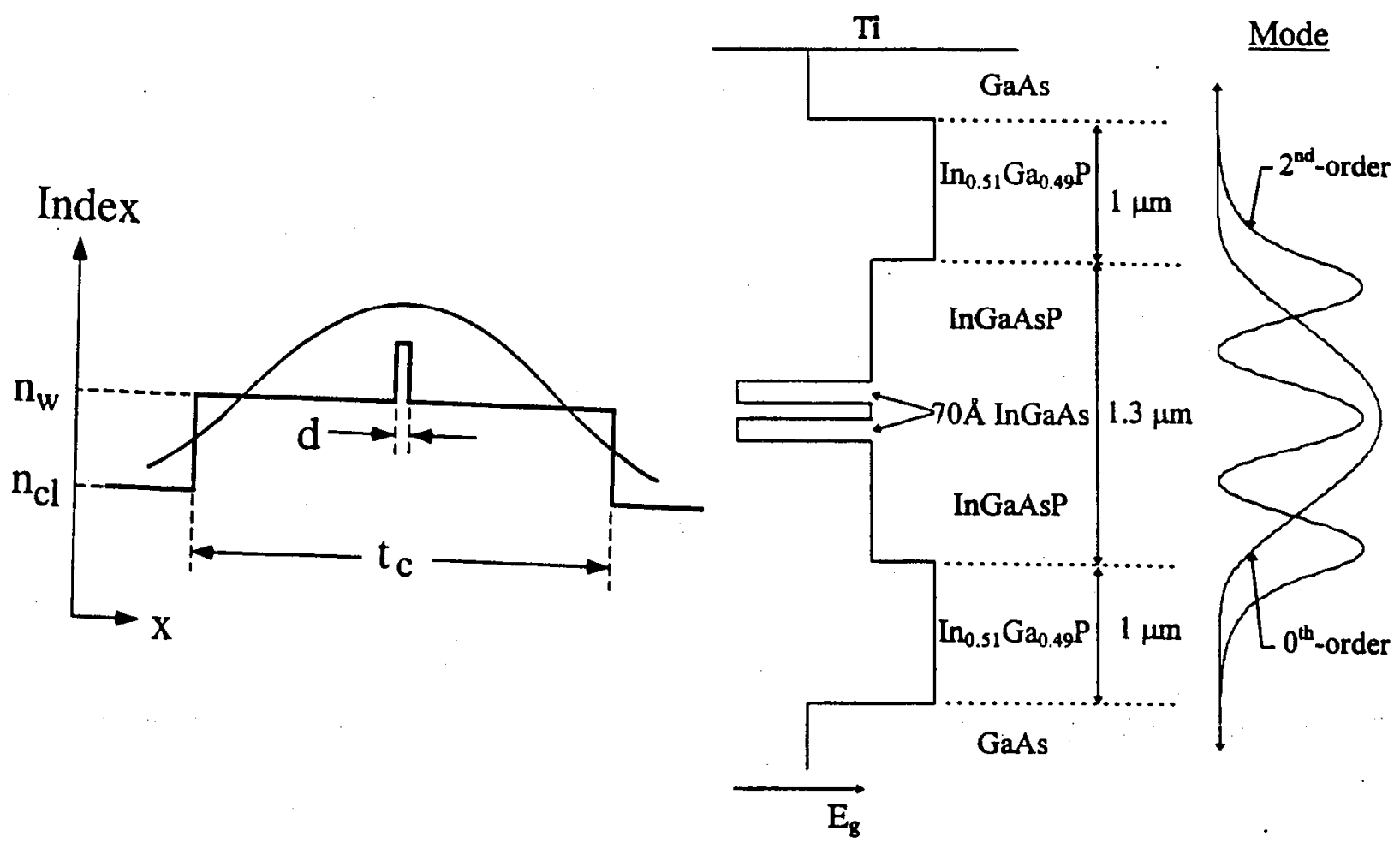

Fig. 1. Schematic representation of BW-type laser structure: effective-index profile and field-intensity profile.
Fig. 2. Schematic representation of Al-free, broad-waveguide $0.97 \mu \mathrm{m}$-emitting diode laser (Ref. 11).

\section{3. $0.97 \mu \mathrm{M}-E M I T T I N G$ INCOHERENT LASERS}

A typical BW structure is shown in Fig. 2. The waveguide is indeed broad: $1.3 \mu \mathrm{m}$ thick, and it supports lasing of only the fundamental transverse mode, since the $2^{\text {nd }}$-order transverse mode is suppressed due to radiation losses to the substrate as well as absorption losses in the metal contact [11]. $\mathrm{CW}$ and quasi-CW

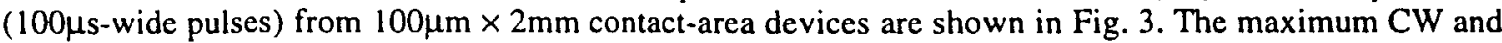
QCW powers are $11 \mathrm{~W}$ [22] and 14.3W[23], which represent the highest powers reported for InGaAs-active lasers, and, for that matter, for any type of conventionally facet-passivated, $100 \mu \mathrm{m}$-stripe diode lasers. The wallplug efficiency at $10.6 \mathrm{~W}$ is [11] $40 \%$, itself a record for such high power levels. 


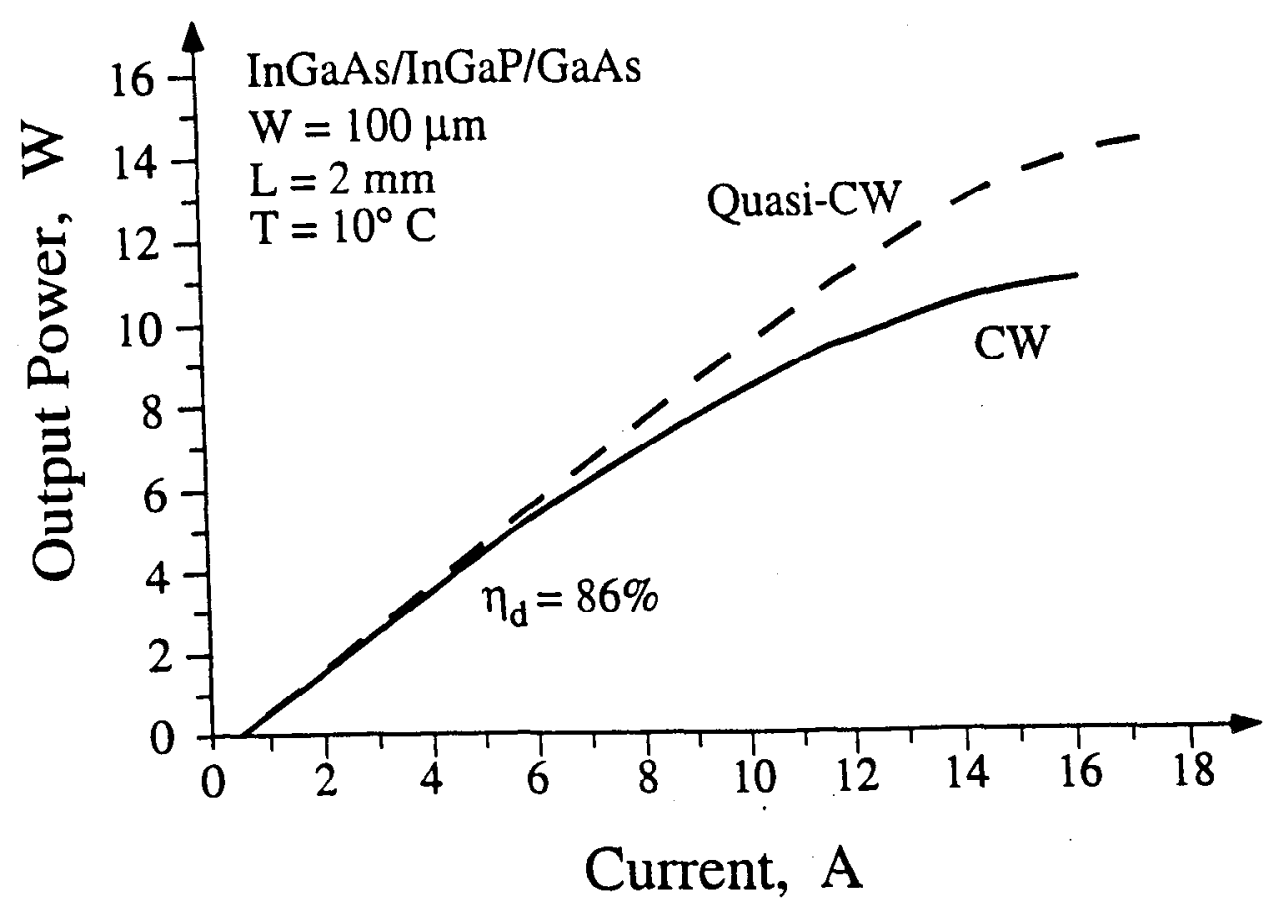

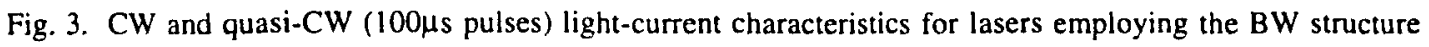
shown in Fig. 2. The devices are mounted on Cu heatsinks, and have 3\%/95\% frondback-faccet reflectivities.

The reasons for the record-high $\mathrm{CW}$ power and wallplug efficiency are:

1. High $\mathrm{d} / \Gamma$ value $(0.66 \mu \mathrm{m})[11]$

2. High $\overline{\mathrm{P}}_{\text {COMD }}$ value $\left(18.5 \mathrm{MW} / \mathrm{cm}^{2}\right)[11]$

3. Temperature insensitive [11] external differential quantum efficiency, $\eta_{\mathrm{D}}: 3 \%$ drop from $20^{\circ}$ to $70^{\circ} \mathrm{C}$; which corresponds to a high value for the characteristic temperature [24], $\mathrm{T}_{1}: 1800 \mathrm{~K}$

4. Low series resistance, $R_{\mathrm{S}}: 26-28 \mathrm{~m} \Omega$; which is at most half that for AlGaAs-based devices of same contact-stripe area.

For relatively short devices (i.e., $0.5 \mathrm{~mm}$ ) $0.97 \mu \mathrm{m} \mathrm{BW-SCH}$ structures hold the record for the highest wallplug efficiency [25] (66\%) reported for diode lasers, and, for that matter, for any type of lasers.

\section{4. $\quad \overline{\mathbf{P}}_{\text {COMD }}$ FOR CONVENTIONALLY FACET PASSIVATED LASERS}

Table I shows $\overline{\mathrm{P}}_{\text {COMD }}$ values computed for various types of $100 \mu \mathrm{m} \times(1.5-2 \mathrm{~mm})$ contact-area diode lasers. The fact that In-containing active-region devices have the highest $\overline{\mathrm{P}}_{\text {COMD }}$ values, while Al-containing activeregion devices have the lowest values is consistent with the fact that AIGaAs material has much higher surface recombination velocity, s, than InGaAs material [26], and that $\overline{\mathrm{P}}_{\text {COMD }}$ is inversely propoitional [13] with s.

Several interesting observations can be made: 1) Addition of $10-20 \%$ In to the active region causes a $50-$ $60 \%$ increase in $\overline{\mathrm{P}}_{\text {COMD }}$ for a given active-region material; 2) GaAs has $40-50 \%$ higher $\overline{\mathrm{P}}_{\text {ComD }}$ than $\mathrm{Al}_{0.07} \mathrm{Ga}_{0.93} \mathrm{As}$ (commonly used for $0.81 \mu \mathrm{m}$ lasers).

\section{0.73-0.81 $\mu \mathrm{m}-$ EMITTING INCOHERENT LASERS}

At $0.81 \mu \mathrm{m}$, a wavelength of significant importance, since that is where pumping of Nd:YAG solid-state lasers occurs, two Al-free active regions can be used: InGaAsP $[1,2,12]$ or $\mathrm{GaAs}[17,27,28]$. Based on Table I, one expects for InGaAsP-active devices reliable powers at least twice those of AIGaAs-active 


\begin{tabular}{|c|c|}
\hline Active-Region Material & $\overline{\mathbf{P}}_{\text {comp }}$ \\
\hline InGaAs $(\lambda \sim 0.92-0.98 \mu \mathrm{m})^{1-3}$ & $18-19 \mathrm{MW} / \mathrm{cm}^{2}$ \\
\hline $\operatorname{InGaAsP}(\lambda \sim 0.81 \mu \mathrm{m})^{4}$ & $18-19 \mathrm{MW} / \mathrm{cm}^{2}$ \\
\hline $\operatorname{InAlGaAs}(\lambda \sim 0.81 \mu \mathrm{m})^{5}$ & $13-14 \mathrm{MW} / \mathrm{cm}^{2}$ \\
\hline $\mathrm{GaAs}^{5}(\lambda \sim 0.81-0.87 \mu \mathrm{m})^{6-8}$ & $10-12 \mathrm{MW} / \mathrm{cm}^{2}$ \\
\hline $\mathrm{Al}_{0.07} \mathrm{Ga}_{0.93} \mathrm{As}(\lambda \sim 0.81 \mu \mathrm{m})^{8.9}$ & $8-9 \mathrm{MW} / \mathrm{cm}^{2}$ \\
\hline $\mathrm{Al}_{0.13} \mathrm{Ga}_{0.87} \mathrm{As}(\lambda \sim 0.78 \mu \mathrm{m})^{8}$ & $\sim 5 \mathrm{MW} / \mathrm{cm}^{2}$ \\
\hline
\end{tabular}

1. A. Al-Muhanna et al., Appl. Phys. Lett., 73, 1182 (1998)

2. S. O'Brien et al., Electron. Lett., 33, 1869 (1997)

3. X. He et al., Electron Lett., 34 (1998)

4. J.K. Wade et al., Appl. Phys. Lett., 72, 4 (1998) and El. Lett., 34, 1100 (1998)

5. X. He, private communication

6. D.Z. Garbuzov et al., Proc. SPIE, 2682, 20 (1996)

7. Y. Oeda et al., private communication (CLEO 48 Paper CMDI)

8. K. Shigihara et al., IEEE J. Quantum Electron, QE-27, 1537 (1991)

9. Y. Yamada, private communication

Table I. $\bar{P}_{C O M D}$ values for conventionally facet passivated lasers of $100 \mu \mathrm{m} \times(1.5-2 \mathrm{~mm})$ stripe-contact area.

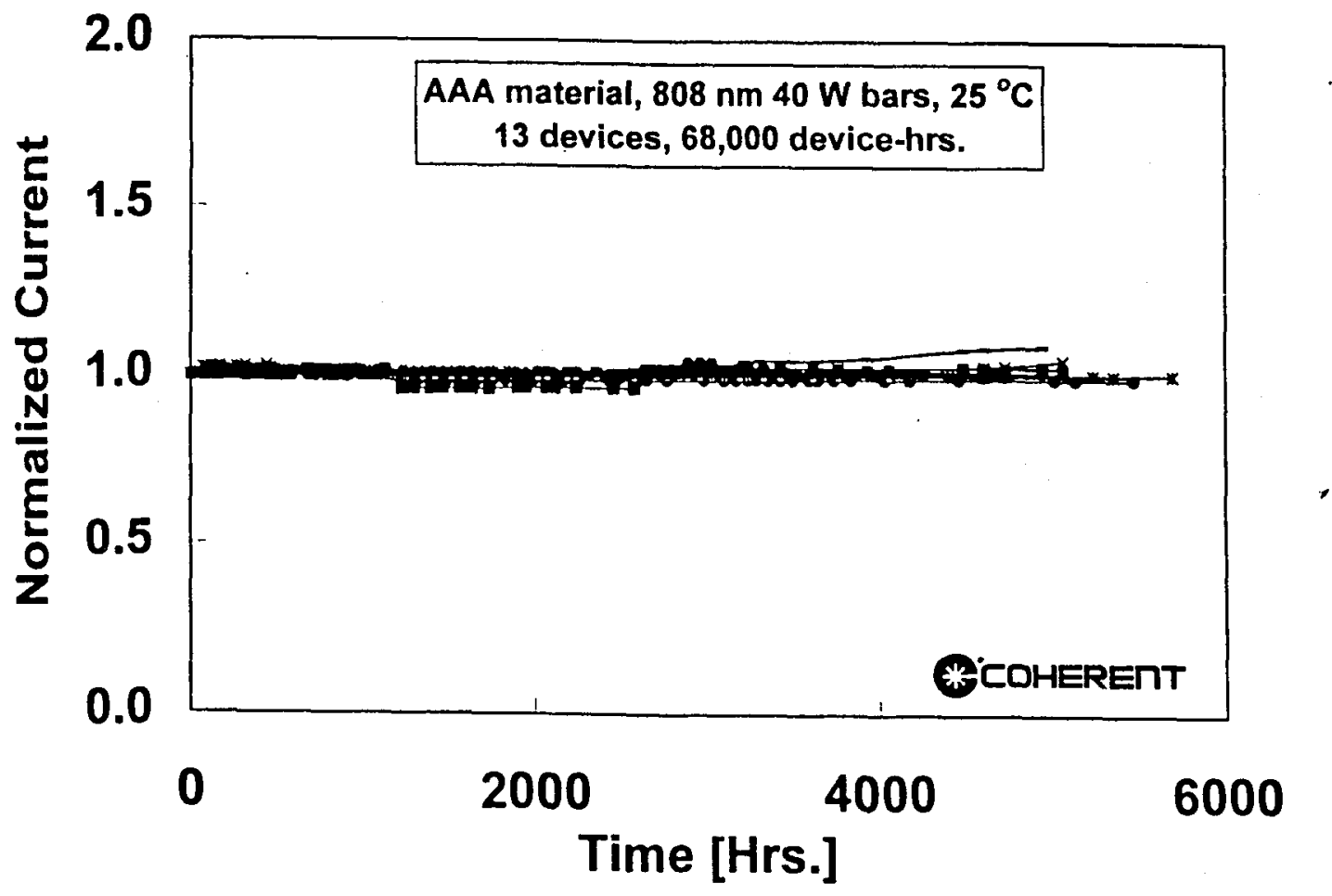

Fig. 4. Lifetests at $40 \mathrm{~W} \mathrm{CW}$ for ALFA-type $0.81 \mu \mathrm{m}$-emitting, $1 \mathrm{~cm}$-long laser bars (Refs. 2 and 30). 
devices, and for GaAs-active devices, reliable powers 40-50\% higher than for AlGaAs-active devices. Reported experimental data confirm these predictions: InGaAsP-active $0.81 \mu \mathrm{m} 1 \mathrm{~cm}$-long bars have shown extensive reliability $[2,29]$ at $40 \mathrm{~W} \mathrm{CW}$ (Fig. 4) vs. the $20 \mathrm{~W}$ value for AlGaAs-active bars, while $100 \mu \mathrm{m}$ stripe GaAs-active devices have shown good reliability $[27,28]$ at $2 \mathrm{~W} \mathrm{CW}$ compared to $1.2 \mathrm{~W}$ reliable power from $100 \mu \mathrm{m}$-stripe AlGaAs-active devices. Furthermore, the InGaAsP-active technology, being relatively undeveloped, has the potential to provide $60 \mathrm{~W}$ reliable $\mathrm{CW}$ power from $1 \mathrm{~cm}$ bars, just as achieved [30] at $\lambda=0.915 \mu \mathrm{m}$ for InGaAs-active bars. [InGaAs $(\lambda=0.97-0.98 \mu \mathrm{m})$ and $\operatorname{InGaAsP}(\lambda=$ $0.81 \mu \mathrm{m}$ ) have virtually the same $\overline{\mathrm{P}}_{\text {COMD }}$, as seen from Table I.]

Below $0.8 \mu \mathrm{m}$, the situation is summarized in Table II. For the $0.78-0.80 \mu \mathrm{m}$ region, $40 \mathrm{~W}$ reliability at both $0.795 \mu \mathrm{m}$ [3] and $0.78 \mu \mathrm{m} \mathrm{[31]} \mathrm{has} \mathrm{been} \mathrm{reported,} \mathrm{while} \mathrm{InAlGaAs-active} \mathrm{bars} \mathrm{provide} \mathrm{only} \mathrm{15-20W} \mathrm{at}$ $\lambda=0.795 \mu \mathrm{m}$. For the rest of the wavelength range (i.e., $0.73-0.78 \mu \mathrm{m}$ ), reliability has been demonstrated from $100 \mu \mathrm{m}$-stripe devices at $0.73 \mu \mathrm{m}$ by two different research groups $[19,32]$, while InAlGaAs-active devices have been unreliable $[5,6]$ with compelling evidence that the cause is bulk degradation [6]. $0.5 \mathrm{~W}$ reliability data at $\lambda=0.73 \mu \mathrm{m}$ from InGaAsP-active devices [33] are shown in Fig. 5.

$\lambda(\mu \mathrm{m}) \backslash$

Active

$0.78-0.80$

40W rel. at $0.795 \mu \mathrm{m}^{1}$
and $0.78 \mu \mathrm{m}^{2}(1 \mathrm{~cm}$ bars $)$

$$
\begin{aligned}
& 0.5 \mathrm{~W} \text { at } 0.73 \mu \mathrm{m}^{3,4} \\
& (100 \mu \mathrm{m} \text { stripe }) \\
& >3000 \mathrm{hr} \text {; ongoing }
\end{aligned}
$$

\author{
InAlGaAs \\ $15-20 \mathrm{~W}$ rel. at $0.795 \mu \mathrm{m}$ \\ (1 $\mathrm{cm}$ bars)
}

\author{
Not reliable $e^{5,6}$ \\ Bulk Degradation \\ $\underline{0.75 \mu \mathrm{m}:}$ \\ $\sim 400 \mathrm{hr}(1 \mathrm{~W} / 100 \mu \mathrm{m})^{6}$ \\ $\underline{0.73 \mu \mathrm{m}:}$ \\ $\sim 500 \mathrm{hr}(0.25 \mathrm{~W} / 100 \mu \mathrm{m})^{5}$ \\ $\sim 70 \mathrm{hr}(1 \mathrm{~W} / 150 \mu \mathrm{m})^{6}$
}

Table II. Results for lasers emitting between $0.73 \mu \mathrm{m}$ and $0.8 \mu \mathrm{m}$. References $1,2,3,4,5$, and 6 in the table correspond to Refs. 3, 31, 32, 19, 5, and 6, respectively.

\section{LARGE-APERTURE COHERENT DEVICES $(\lambda=0.97-0.98 \mu \mathrm{m})$}

There has been significant effort over the last decade for achieving watt-range coherent powers from largeaperture $(>100 \mu \mathrm{m})$ diode lasers. Devices such as the fanout-type master-oscillator power-amplifier (MOPA) [34] and the $\alpha$-distributed-feedback (DFB) laser [35] have displayed high diffraction-limited, single-frequency powers. However, such devices, having weak or no lateral-mode confinement, possess inherent instabilities [36-39] due to refractive-index variations induced by thermal gradients and/or inected carriers, thus raising serious issues of long-term stability and reliability. Therefore, there is a need for coherent large-aperture devices which not only select fundamental-mode operation but also maintain a stable mode to high drive levels. 
Appendix A - Final report from University of Wisconsin

\section{$0.73 \mu \mathrm{m}$ Preliminary Lifetest $0.5 \mathrm{~W} \mathrm{CW}, 20^{\circ} \mathrm{C}, 100 \mu \mathrm{m}$ Stripe}

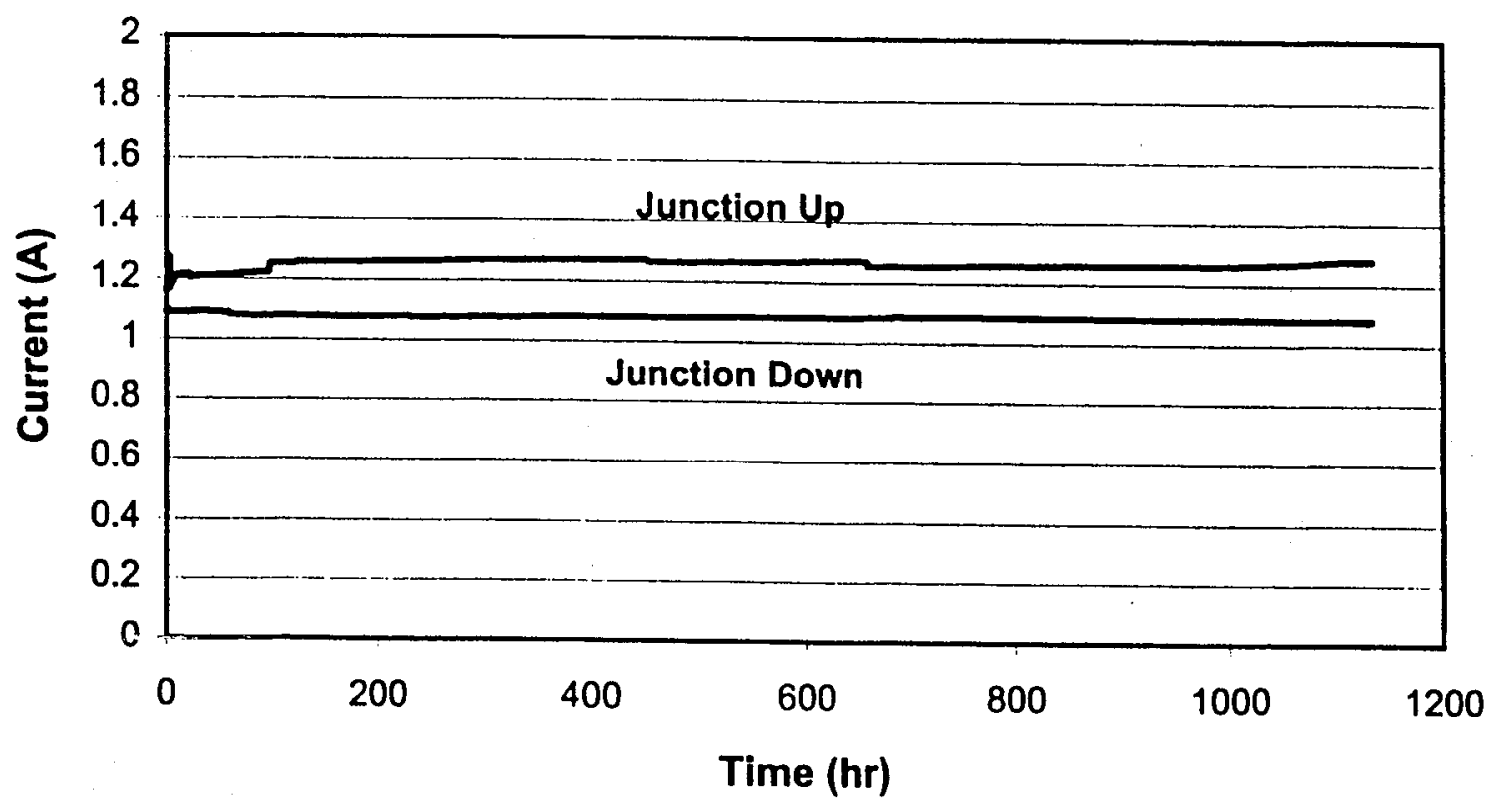

Fig. 5. Lifetests of $0.73 \mu \mathrm{m}$-emitting ALFA devices (Ref. 33).

As in the case of single-element devices, large-aperture emitters can achieve lateral-mode stability only by introducing a structure with strong built-in index guiding $(\Delta n>0.01)$ [40]. Since the fabrication of such structures involves regrowth(s), Al-free materials are ideal to use due to ease of regrowth over oxide-free surfaces.

The large-index structures of wide aperture are so-called "photonic-lattice" structures for which one uses (lateral) gain modulation to select a single lateral travelling-wave mode [40]. There are two types of such devices: ARROW-type lasers [7, 41] and ROW-type laser arrays [40].

ARROW-type devices have a low-index core and mode-selective lateral reflectors [41], and have shown $0.5 \mathrm{~W}$ in a stable, single-lobe beam [41] as well as $0.4 \mathrm{~W} \mathrm{CW}$ in a stable, diffraction-limited (D.L.) beam [7] $(\lambda=0.98 \mu \mathrm{m})$. The potential for ARROW devices is: $0.8-1.0 \mathrm{~W} \mathrm{CW}$ stable, D.L.-beam operation $(\lambda=$ $0.98 \mu \mathrm{m}$ ) from devices of $8-10 \mu \mathrm{m}$-wide aperture.

ROW laser arrays have the optical field peaking in low-index, high-gain regions and resonant global interelement coupling via travelling waves [40]. From AlGaAs-based devices $0.5 \mathrm{~W} \mathrm{CW}$ and $2.1 \mathrm{~W}$ peak-

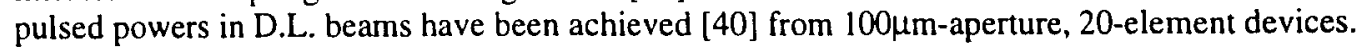

More recently, employing the Al-free technology at $\lambda=0.97 \mu \mathrm{m} 10 \mathrm{~W}$ peak pulsed power in a near-D.L. beam has been reported [8] from $200 \mu \mathrm{m}$-aperture, 40 -element arrays. However, those devices had a relatively small $\Delta \mathrm{n}(0.035)$ which in $\mathrm{CW}$ operation, due to thermal lensing, caused beams 4-5 D.L. at IW power level.

Most recently we developed [42] 40-element ROW arrays of large index step $(\Delta n=0.1)$. Large $-\Delta n$ devices are attractive since they are virtually insensitive to gain spatial hole burning [43], and are less sensitive to thermal lensing. A typically good result is shown in Fig. 6 . The beam is near-D.L. $(-2 \times$ D.L.) up to $1.6 \mathrm{~W} \mathrm{CW}$, and $9 \mathrm{x}$ threshold. The price for coherency is not too high: wallplug efficiency, $\eta_{\mathrm{p}}$, values of $24 \%$ and $23 \%$ are obtained at $0.8 \mathrm{~W}$ and $1.6 \mathrm{~W} \mathrm{CW}$, respectively. At $1.6 \mathrm{~W}$ power level, the coherent power in the main lobe is $1.0 \mathrm{~W}$. Thus high- $\Delta \mathrm{n}$ ROW arrays have proven stable-beam, watt-range coherent powers. The potential is for stable, near-D.L.-beam powers as high as $3 \mathrm{~W} C W$. 
$\lambda=0.985 \mu \mathrm{m}$

$0.8 \mathrm{~W}$

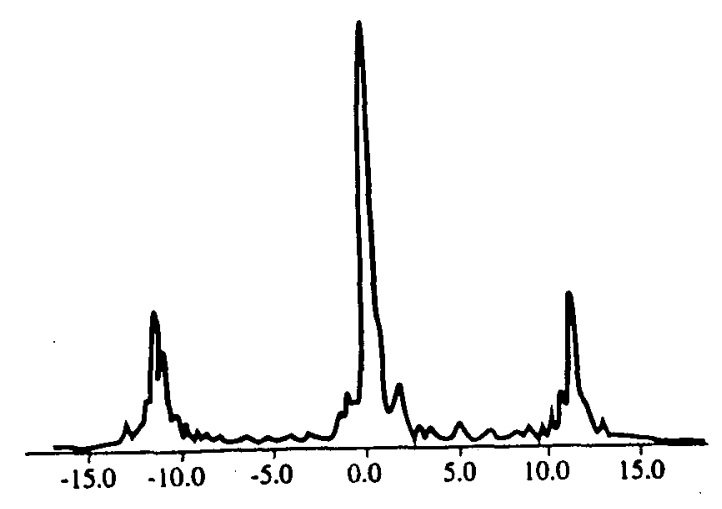

Angle (Degrees)

$\theta_{1 / 2}=0.61^{\circ}=2.0 \times$ D.L.

$\eta_{\mathrm{p}}=24 \%$

\section{$1.6 \mathrm{~W}$}

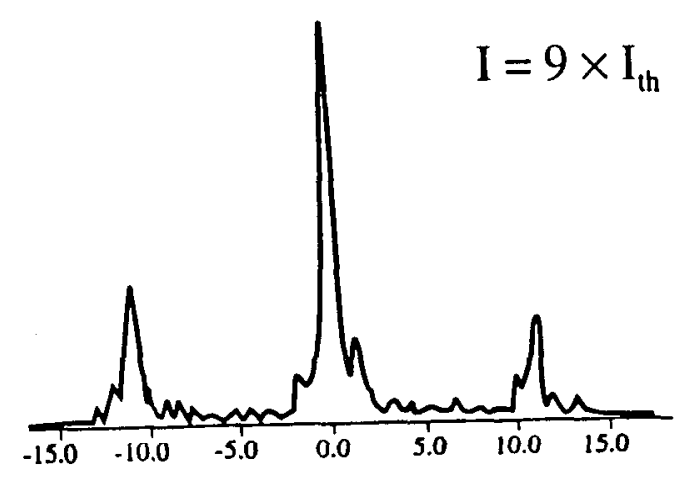

Angle (Degrees)

$\theta_{1 / 2}=0.67^{\circ}=2.2 \times$ D.L.

$\eta_{\mathrm{p}}=23 \%$

\section{$1.0 \mathrm{~W}$ power in main lobe}

Fig. 6. CW far-field patterns of 40 -element near-resonant antiguided arrays (Ref. 42 ). $\eta_{p}$ is the wallplug efficiency.

\section{CONCLUSIONS}

In conclusion, Al-free diode lasers have demonstrated record-high performances at several wavelengths, have "opened" the $0.70-0.78 \mu \mathrm{m}$ wavelength region for use, and allow for the fabrication of stable-beam, largeaperture coherent devices.

\section{ACKNOWLEDGEMENTS}

The author is grateful for the technical efforts of the UW-Madison team: L. J. Mawst, A. Al--Muhanna, T. Earles, J. Lopez, J. K: Wade and H. Yang; as well as the technical efforts of researchers from Sarnoff Corp.: D. Z. Garbuzov, J. C. Connolly, and R. U. Martinelli. The work was in part supported by the Air Force Phillips Laboratory under Contract No. F29601-96-C-0140.

\section{REFERENCES}

1. J. K. Wade, L. J. Mawst, D. Botez, R. F. Nabiev and J. A. Morris, Appl. Phys. Lett., 2ㅡ, 4 (1998).

2. R. F. Nabiev, J. Aarik, H. Asonen, P. Bournes, P. Corvini, F. Fagg, M. Finander, M. Jansen, J. Nappi, K. Rakemus and A. Salokatve, Conf. Dig. 1998 IEEE 16 Int. Semicond. Laser Conf.,. Nara, Japan, 4-8 Oct. 1998, pp. 43-44.

3. P. Bournes, H. Asonen, F. Fang, M. Finander, M. Jansen, R. F. Nabiev, J. Nappi, K. Rakemus, and A. Salokatve, Conf. Proc. IEEE LEOS '98 Ann. Mtg., Orlando, Fla., 1-4 Dec. 1998, pp. 276 -277 . 
Appendix A - Final report from University of Wisconsin

4. D. Botez, Conf. Proc. IEEE LEOS '98 Ann. Mtg., Orlando, Fla., 1-4 Dec. 1998, pp. 274-275.

5. M. A. Emanuel, N. W. Carlson and J. A. Skidmore, IEEE Photon Tech. Lett., ㅇ, 1291 (1996).

6. J. S. Roberts, J. P.R. David, L. Smith and P.L. Tihanyi, J. Cryst. Growth, 195, 668 (1998).

7. A. Bhattacharya, L. J. Mawst, M. Nesnidal, J. Lopez, and D. Botez, Electron. Lett. 32, 657 (1996).

8. H. Yang, L. J. Mawst, M. Nesnidal, J. Lopez, A. Bhattacharya, and D. Botez, Electron. Lett., 33, 136 (1997).

9. T. Earles, L. J. Mawst and D. Botez, Appl. Phys. Lett., 73, 2072 (1998).

10. M. Sagawa, T. Toyonaka, K. Hiramoto, K. Shinoda, and K. Uomi, IEEE J. Sel. Top. Quantum Electron. 1, 189 (1995).

11. A. Al-Muhanna, L. J. Mawst, D. Botez, D. Garbuzov, R. U. Martinelli, J. C. Connolly, Appl. Phys. Lett., 73, 1182, (1998).

12. J. K. Wade, L. J. Mawst, D. Botez and J. A. Morris, Electron. Lett., 34, 1100 (1998).

13. J. S. Yoo, H. H. Lee and P. S. Zory, IEEE Photon. Tech. Lett., 3, 594 (1991),

14. R. Schatz and C. Bethea, J. Appl. Phys., 76, 2509 (1994).

15. L. J. Mawst, A. Bhattacharya, J. Lopez, D. Botez, D.Z. Garbuzov, L. DeMarco, J. C. Connolly, M. Jansen, F. Fang and R. F. Nabicv, Appl. Phys. Lett., 69, 1532 (1996).

16. I. B. Petrescu-Prahova, M. Buda and T. G. van de Roer, IEICE Trans Electron, E77-C, 1472 (1994).

17. D. Z. Garbuzov, J. H. Abeles, N. A. Morris, P. D. Gardner, A. R. Triano, M. G. Harvey, D. B. Gilbert and J. C. Connolly, Proc. SPIE, 2682, 20 (1996).

18. N. Lichtenstein, R. Winterhoff, F. Scholz, H. Schweizer, Tech. Dig. IEEE $16^{\text {th }}$ International Semiconductor Laser Conf., Nara, Japan, 4-8 Oct. 1998, p. 51.

19. G. Erbert, H. Wenzel, A. Bhattacharya, F. Bugge, A. Knauer, J. Maege, W. Pitroff, J. Sebastian and A. Thics, Conf. Proc. IEEE Lascrs and Electro-Optics Soc. 1998 Ann. Mtg., Orlando, FL, 1-4 Dec. 1998, Paper PD 2.1.

20. D. Garbuzov, R. Menna, R. Martinelli, J. Abeles, J. Connolly, Electron. Lett., 33, 1635 (1997).

21. D. Garbuzov, R. Menna, H. Lee, R.U. Martinelli, J. C. Connolly, L. Xu, S.R. Forrest, Conf. on InP and Related Compounds, Hyannis, MA, 11 May 1997, pp. 551-554.

22. D. Z. Garbuzov, Tech. Dig. IEEE/OSA Conf. On Lasers and Electro-Optics '98, San Francisco, CA (1998), 6, 10.

23. A. Al-Muhanna, L. Mawst, D. Botez, D. Garbuzov, R. Martinelli, J. Connolly, Appl. Phys. Lett., 71, 1142 (1997).

24. L. J. Mawst, A. Bhattacharya, M. Nesnidal, J. Lopez, D. Botez, J. A. Morris, and P. Zory, Appl. Phys. Lett., 67, 2901 (1995).

25. D. Botez, L. J. Mawst, A. Bhattacharya, J. Lopez, J. Li, T. F. Kuech, V. P. Iakovlev, G. I. Suruceanu, A. Caliman, and A. V. Syrbu, Electron. Lett., 32, 2012 (1996).

26. E. Yablonovitch, R. Bhat, C. E. Zah, T. J. Gmiltter, and M.A. Koza, Appl. Phys. Lett., 60, 371 (1992).

27. Y. Oeda et al., CLEO '98, San Francisco, May '98.

28. Whitaker et al., Compound Semicond., Oct. ' 98. 
29. X. He, S. Srimivasan, V. Zarate and R. Patel, Conf. Proc IEEE 16th Int. Semicond. Laser Conf., Nara, Japan, 4-8 Oct. 1998, pp. 123-124.

30. D. Botez, Laser Focus World, pp. 16-19, Dec. 1998.

31. Laser Focus World, p. 37, Dec. '98.

32. A. Al-Muhanna, J. K. Wade, T. Earles, J. Lopez and L. J. Mawst, Appl. Lett., 73, 2869 (1998).

33. L. J. Mawst, A. Al-Muhanna and T. Earles, private communication.

34. D. F. Welch and D. G. Mehuys, Diode Laser Arrays, D. Botez and D. R. Scifres, eds., Cambridge University Press, Cambridge, UK, pp. 72-122 (1994).

35. K. M. Dzurko, R. J. Lang. D. F. Welch, D. R. Scifres and A. Hardy, Proc. IEEE/LEOS 1995 Annual Mtg., 2, 400 (1995).

36. L. Goldberg, M. Surette and D. Mehuys, Appl. Phys. Lett., 62, 5, 2304 (1993).

37. S. Ramanujan and H. G. Winful, IEEE J. Quantum Electron, 32, 784 (1996).

38. A. Schoenfelder, S. D. DeMars, K. M. Dzurko, R. J. Lang, D. F. Welch, D. R. Scifres, and A. Hardy, Tech Dig. 15th IEEE International Semiconductor Laser Conference, Haifa, Israel, Paper PDP7, 13-18 October 1996.

39. D. J. Bossert, G. C. Dente and M. L. Tilton, Proc. SPIE, 3001, 63 (1997).

40. D. Botez, Diode Laser Arrays, D. Botez and D. R. Scifres, eds., Cambridge University Press, Cambridge, UK, pp. 1-71 (1994).

41. L. J. Mawst, D. Botez, C. Zmudzinski and C. Tu, IEEE Photon. Tech. Lett., 4, 1204 (1992).

42. H. Yang, J. Lopez, L. J. Mawst, J. K. Wade, T. Earles and D. Botez, Proc. SPIE Conference "InPlane Semiconductors Lasers III," 3628 (1998).

43. R. F. Nabiev and D. Botez, IEEE J. Special Topics Quantum Electron, 1, 138 (1995). 